\title{
Celastrol induces the apoptosis of breast cancer cells and inhibits their invasion via downregulation of MMP-9
}

\author{
CHUNLIU MI ${ }^{2,3 *}$, HUI SHI ${ }^{2,3^{*}}$, JUAN MA $^{1,2}$, LI ZHUO HAN ${ }^{4}$, JUNG JOON LEE $^{2}$ and XUEJUN JIN ${ }^{1,2}$ \\ ${ }^{1}$ Key Laboratory of Natural Resources of Changbai Mountain and Functional Molecules, Ministry of Education, \\ College of Pharmacy; ${ }^{2}$ Molecular Cancer Research Center; ${ }^{3}$ Key Laboratory of Natural Resources of Changbai Mountain \\ and Functional Molecules, Ministry of Education, Department of Chemistry, Yanbian University, Yanji, Jilin 133002; \\ ${ }^{4}$ Department of Pharmacy, Jilin Province People's Hospital, Changchun, Jilin 130021, P.R. China
}

Received June 7, 2014; Accepted September 18, 2014

DOI: $10.3892 /$ or.2014.3535

\begin{abstract}
Celastrol is a quinone methide triterpene derived from Tripterygium wilfordii Hook F., a plant used in traditional medicine. In the present study, we reported that celastrol potentiated tumor necrosis factor- $\alpha$ (TNF- $\alpha$ )-induced apoptosis, affected activation of caspase-8, caspase-3 and PARP cleavage, and inhibited the expression of anti-apoptotic proteins such as cellular inhibitor of apoptosis protein 1 and 2 (cIAP1 and cIAP2), cellular FLICE-inhibitory protein (FLIP), and B-cell lymphoma 2 (Bcl-2). In addition, celastrol significantly reduced the invasion of MDA-MB-231 human breast cancer cells after TNF- $\alpha$ stimulation. As matrix metalloproteinase-9 (MMP-9) plays a critical role in tumor metastasis, we analyzed its expression with celastrol treatment. Western blot analysis and real-time PCR showed that celastrol dose-dependently suppressed TNF- $\alpha$-induced MMP-9 gene expression at both the mRNA and protein levels in MDA-MB-231 cells. Taken together, our findings indicate that celastrol may be a potential candidate for breast cancer chemotherapy.
\end{abstract}

Correspondence to: Professor Jung Joon Lee, Molecular Cancer Research Center, Yanbian University, Yanji, Jilin 133002, P.R. China E-mail: jjlee0908@gmail.com

Professor Xuejun Jin, Key Laboratory of Natural Resources of Changbai Mountain and Functional Molecules, Ministry of Education, College of Pharmacy, Yanbian University, Yanji, Jilin 133002, P.R. China

E-mail: xjjin@ybu.edu.cn

${ }^{*}$ Contributed equally

Abbreviations: ECM, extracellular matrix; MMPs, matrix metalloproteinases; TNF- $\alpha$, tumor necrosis factor- $\alpha$; PMA, phorbol 12-myristate 13-acetate; NF- $\kappa \mathrm{B}$, nuclear factor- $\kappa \mathrm{B}$; AP-1, activator protein-1; cIAP1, cellular inhibitor of apoptosis 1; FLIP, cellular FLICE-inhibitory protein; Bcl-2, B-cell lymphoma 2

Key words: celastrol, apoptosis, MMP-9, metastasis, breast cancer

\section{Introduction}

Breast cancer is the predominant type of cancer in industrialized countries and the second leading cause of cancer-related mortality in women (1). Metastasis, the development of secondary tumors at a distant site, remains the major cause of cancer mortality (2). Cancer metastasis is a complex process which involves important steps of cell migration and invasion (3). Therefore, the control of metastasis and invasion represents an important therapeutic target. Molecular mechanisms of cancer cell invasion and metastasis involve a complex series of events. One such early event involves proteolytic degradation of the extracellular matrix (ECM) components, which provides biochemical and mechanical barriers to cell movement in cancer cells $(4,5)$. ECM degradation requires extracellular proteinases, of which matrix metalloproteinases (MMPs) play a critical role in breast cancer.

MMPs are a family of zinc- and calcium-dependent endopeptidases, consisting of four subclasses based on substrate including collagenases, gelatinases, stromelysins and membrane-associated MMPs according to substrate specificity and domain homologies $(6,7)$. Elevated MMP levels are functionally linked to metastasis in many tumors including breast (2). Both MMP-2 and MMP-9 are the key enzymes that control the rate of cell invasion and metastasis (8). Although these two gelatinases (MMP-2 and MMP-9) have similar properties, their gene expression is differentially and specifically regulated by distinct regulatory elements in their promoter regions (7). MMP-2 is commonly constitutively present in tissues and it is maximally expressed in malignant neoplasms as part of the host response to the presence of neoplastic cells, rather than as part of an initial response to invasion (9). In contrast, synthesis and secretion of MMP-9 can be stimulated by a variety of growth factors and inflammatory cytokines during pathological processes and by agents such as phorbol 12-myristate 13-acetate (PMA) and tumor necrosis factor- $\alpha$ (TNF- $\alpha$ ) (9-11). This difference can be explained by the presence of inducible promoter elements, such as the nuclear factor- $\kappa \mathrm{B}(\mathrm{NF}-\kappa \mathrm{B})$ and activator protein-1 (AP-1) binding sites, which are involved in the regulation of the MMP-9 gene transcription, but not in that of MMP-2 $(12,13)$. Therefore, it has been suggested that the 
regulation of MMP-9 expression is a possible approach for the development of anti-metastatic drugs $(14,15)$.

Similar to other solid tumors, breast cancer is difficult to treat. Some traditional methods, such as chemotherapy, may cause strong side-effects and drug resistance in patients. Therefore, there is a continuing need to find novel, efficient and less toxic cancer therapeutic molecules. Natural products, such as plant-derived drugs, play an increasingly important role in cancer treatment due to their fewer side-effects and high efficacy. One of these strategies is to determine the ability and mechanism of novel anticancer agents to induce apoptosis in cancer cells. Apoptosis, also known as programmed cell death, is a type of cell death distinct from necrosis that plays an important role in the regulation of various physiological and pathological conditions (16). Apoptosis induction is regarded as a major therapeutic target for cancer chemotherapy (17-19). In mammalian cells, apoptosis is regulated by the activation of two signaling pathways, an extrinsic and an intrinsic one. The extrinsic pathway is regulated by death receptors on the plasma membrane. In this pathway, ligand binding to the receptors induces the activation of the caspase cascade. The intrinsic pathway is regulated by mitochondrial proteins (20). Under most circumstances, activation of either pathway eventually leads to proteolytic cleavage and thus activation of caspases, a family of cysteine proteases that act as common death effector molecules (21). Accordingly, caspases are responsible for many biochemical and morphological hallmarks of apoptotic cell death by cleaving a range of substrates in the cytoplasm or nucleus (21). Several intracellular anti-apoptotic molecules, such as members of the anti-apoptotic B-cell lymphoma 2 (Bcl-2) and cellular inhibitor of apoptosis protein (cIAP) families, as well as cellular FLICE-inhibitory protein (FLIP), have been shown to inhibit the apoptotic signaling cascade via inhibition of mitochondrial cytochrome $c$ release, apoptosome formation and recruitment of procaspase- 8 to the death receptor domain (22-25). Receptor-mediated activation of caspase- 8 is followed by activation of caspase- 3 , which cleaves intracellular substrates leading to cell death (26). Then, caspase- 3 cleaves several target proteins, one of which is DNA repair enzyme, PARP (27). Deregulation of apoptosis programs can lead to resistance of cancers to current treatment strategies, since the ability to activate cell death programs in cancer cells critically determines the efficacy of current cancer therapies (28). Furthermore, apoptosis of circulating tumor cells can have an impact on the metastatic process $(29,30)$. Targeting the apoptosis pathway in circulating tumor cells may present a means to interfere with metastasis (28).

Celastrol, also known as tripterine, is one such compound that was originally identified from the traditional Chinese medicine Thunder God Vine or Tripterygium wilfordii Hook F. almost three decades ago and is used for the treatment of cancer and other inflammatory diseases (31). Celastrol is also known to inhibit the proliferation of a variety of tumor cells, including leukemia, glioma, prostate and breast cancer cells. The ability of celastrol to modulate the expression of proinflammatory cytokines such as interleukin-1 (IL-1), IL-6, IL-8 and TNF- $\alpha$, to inhibit NF- $\kappa \mathrm{B}$ signaling, and to induce heat shock response and proteasome activity has been reported $(13,32,33)$. Despite the diverse studies on the biological activities of celastrol, the potential of celastrol against breast cancer proliferation and invasion is poorly defined. In the present study, we investigated the underlying pathways involved in inhibiting TNF- $\alpha$-induced anti-apoptotic gene expression and invasion in the human breast cancer line MDA-MB-231 cells by celastrol. The results showed that celastrol induced the apoptosis of breast cancer cells and inhibited their invasion by downregulating MMP-9 expression.

\section{Materials and methods}

Cell culture and reagents. Two human breast cancer cell lines, MCF-7 and MDA-MB-231, were grown in RPMI-1640 supplemented with penicillin $(100 \mathrm{U} / \mathrm{ml})$-streptomycin $(100 \mathrm{U} / \mathrm{ml})$ (Invitrogen, Carlsbad, CA, USA) and 10\% heat-inactivated fetal bovine serum (FBS; HyClone, Logan, UT, USA). Cell cultures were grown to confluence and maintained in a humidified atmosphere at $37^{\circ} \mathrm{C}$ and $5 \% \mathrm{CO}_{2}$. All cells were purchased from American Type Culture Collection (ATCC; Manassas, VA, USA). TNF- $\alpha$ was obtained from R\&D Systems (Minneapolis, MN, USA). Celastrol was isolated from Tripterygium wilfordii and its structure is shown in Fig. 1A. The purity of celastrol was $>98 \%$ in HPLC analysis.

Measurement of cell viability by MTT assay. MCF-7 and MDA-MB-231 cells were seeded at $1 \times 10^{5}$ cells $/ \mathrm{ml}$ in 96-well plates containing $100 \mu \mathrm{l}$ of RPMI-1640 with $10 \%$ FBS and incubated overnight. Celastrol was dissolved in DMSO and DMSO was added to all plates to compensate the same volume of DMSO. After $24 \mathrm{~h}$, the cells were pretreated with different concentrations of celastrol for $1 \mathrm{~h}$, followed by stimulation with or without TNF- $\alpha$ for $24 \mathrm{~h}$. Subsequently, cells were cultured with 3-(4,5-dimethylthiazol-2-yl)-2,5-diphenyltetrazolium bromide (MTT) solution ( $5 \mathrm{mg} / \mathrm{ml}$ ) (Sigma-Aldrich, St. Louis, MO, USA) for $3 \mathrm{~h}$. The viable cells converted MTT to formazan, which generated a blue-purple color after dissolving in $150 \mu \mathrm{l}$ of DMSO. The absorbance at $570 \mathrm{~nm}$ was measured by an ELISA plate reader.

Apoptosis assays. Annexin V-staining was performed using Annexin V-FITC apoptosis detection kit (BD Biosciences, San Diego, CA, USA) following the manufacturer's instructions. Briefly, after incubation, cells were harvested, washed with phosphate-buffered saline ( $\mathrm{pH} 7.4)$, centrifuged, and stained with Annexin V-FITC and $2 \mathrm{mg} / \mathrm{ml}$ propidium iodide in binding buffer (10 mM HEPES, pH 7.4, $140 \mathrm{mM} \mathrm{NaCl}$, $2.5 \mathrm{mM} \mathrm{CaCl}_{2}$ ) for $15 \mathrm{~min}$ at $37^{\circ} \mathrm{C}$ in the dark. The samples were analyzed by flow cytometry using a FACScan flow cytometer. The CellQuest software was used to analyze the data (Becton-Dickinson).

Western blotting. Cell lysates and conditioned media were separated by SDS-polyacrylamide gels and then transferred to a polyvinylidene difluoride membrane (Millipore, Bedford, MA, USA). The membrane was blocked with 5\% skim milk and then incubated with the corresponding antibody. Antibodies for cleaved PARP, cleaved caspase-3, cleaved caspase-8, cIAP1 and cIAP2 were purchased from Cell Signaling Technology (Beverly, MA, USA). Antibodies for MMP-1, MMP-2, MMP-9, Bcl-2 and FLIP were obtained from Santa Cruz Biotechnology (Santa Cruz, CA, USA). Antibody for $\alpha$-tubulin was from 
A

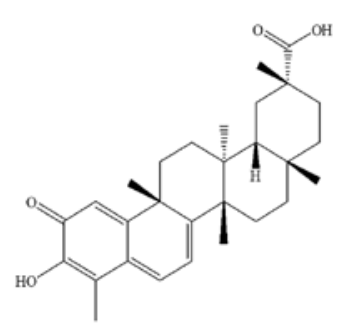

B

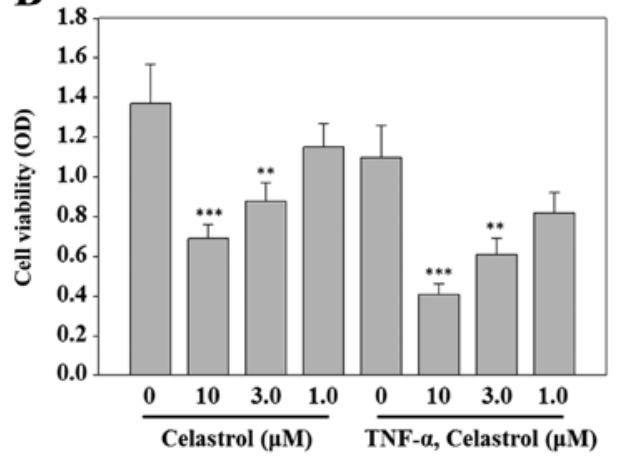

C

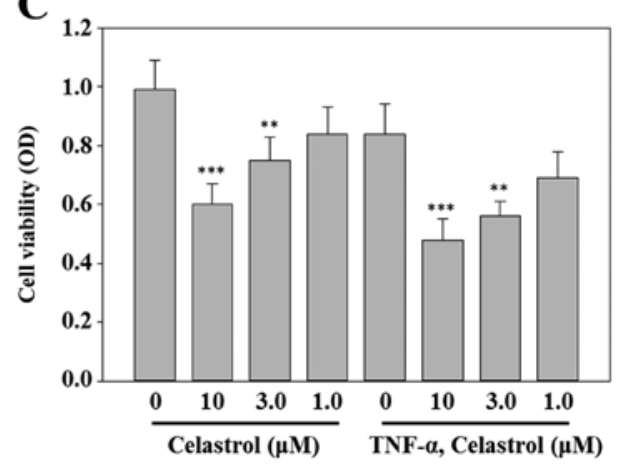

Figure 1. Effect of celastrol on the cell viability of MCF-7 and MDA-MB-231 human breast cancer cells. (A) Structure of celastrol. (B and C) MCF-7 and MDA-MB-231 cells were treated with different concentrations of celastrol (1,3 and $10 \mu \mathrm{M})$ in the presence or absence of tumor necrosis factor- $\alpha$ (TNF- $\alpha)$ $(20 \mathrm{ng} / \mathrm{ml})$. After $24 \mathrm{~h}$ incubation, cell viability was determined by MTT assays. Data are presented as the mean \pm standard deviation of three independent experiments. ${ }^{* *} \mathrm{P}<0.01,{ }^{* * *} \mathrm{P}<0.001$, significant with respect to control.

Sigma-Aldrich. After binding an appropriate secondary antibody coupled to horseradish peroxidase, proteins were visualized by enhanced chemiluminescence according to the manufacturer's instructions (Amersham Pharmacia Biotech, Buckinghamshire, UK).

In vitro invasion assays. The ability of cells to invade through Matrigel-coated filters (invasion) was determined using a modified 24-well Boyden chamber (Corning Costar, Cambridge, MA, USA; $8 \mu \mathrm{m}$ pore size) as was previously described (34). MDA-MB-231 cells were seeded at a density of $5 \times 10^{4}$ cells in $100 \mu \mathrm{l}$ RPMI-1640 containing $10 \%$ FBS in the upper compartment of Transwell. To determine the effect of celastrol, various concentrations of celastrol and TNF- $\alpha$ $(20 \mathrm{ng} / \mathrm{ml})$ were added to the lower or upper compartment of Transwell. After incubation for $24 \mathrm{~h}$ at $37^{\circ} \mathrm{C}$ in $5 \% \mathrm{CO}_{2}$, the cells that did not penetrate the filter were completely wiped out with a cotton swab, and the cells that had migrated to the lower surface of the filter were fixed, stained, and counted in 5 randomly selected microscopic fields (x100) per filter.

Real-time PCR. Total RNA from MDA-MB-231 cells was obtained using RNA Mini kit (Qiagen, Valencia, CA, USA). Total RNA $(2 \mu \mathrm{g})$ was used to perform reverse transcriptionPCR (RT-PCR) using RT-PCR kit (Invitrogen) according to the manufacturer's protocol. The PCR primers were: MMP-1, 5'-AGCTAGCTCAGGATGACATTGATG-3' (sense) and 5'-GCCGATGGGCTGGACAG-3' (antisense); MMP-2, 5'-TGAGCTCCCGGAAAAGATTG-3' (sense) and 5'-TCAG CAGCCTAGCCAGTCG-3' (antisense); MMP-9, 5'-CAACA TCACCTATTGGATCC-3' (sense) and 5'-CGGGTGTAGA GTCTCTCGCT-3' (antisense); GAPDH, 5'-ACCACAGTC CATGCCATCAC-3' (sense) and 5'-TCCACCACCCTGTTG CTGTA-3' (antisense). The oligonucleotide sequences of the reaction products were confirmed by sequencing.

Statistical analysis. All values are expressed as mean \pm SD. A comparison of the results was performed with one-way ANOVA and Tukey's multiple comparison tests (Graphpad Software, Inc., San Diego, CA, USA). Statistically significant differences between groups were defined as P-values $<0.01$.

\section{Results}

Celastrol is cytotoxic to breast cancer cells. To evaluate the effect of celastrol on the viability of breast cancer cells, MCF-7 and MDA-MB-231 cells were exposed to increasing concentrations of celastrol (from 1 to $10 \mu \mathrm{M}$ ) in the presence or absence of TNF- $\alpha$ (20 ng/ml) for $24 \mathrm{~h}$, and the percentage of viable cells was determined using the MTT assay. Celastrol decreased cell viability in a dose-dependent manner in MCF-7 and MDA-MB-231 breast cancer cells (Fig. 1B and C).

Celastrol potentiates TNF- $\alpha$-induced apoptosis. Next, we examined whether celastrol enhances apoptosis by TNF- $\alpha$. Celastrol potentiated TNF- $\alpha$-induced apoptosis, as assessed by Annexin V/PI double staining. As shown in Fig. 2A, combined treatment resulted in a significant increase in the Annexin V-positive cell population $(45.35 \%)$, whereas no treatment $(5.12 \%)$, treatment with TNF- $\alpha$ alone $(25.70 \%)$ or celastrol alone $(15.23 \%$ ) had only slight influence on cell apoptosis. Since caspases are a group of cysteine proteases critical for apoptosis of eukaryotic cells (35), we investigated whether celastrol affects TNF- $\alpha$-induced activation of caspase- 8 and caspase-3. TNF- $\alpha$ alone and celastrol alone did not affect the activation of caspase- 8 or caspase- 3 , whereas cotreatment with TNF- $\alpha$ and celastrol potentiated their activation, as indicated by the presence of cleaved caspases, and this activation was observed at a concentration even as low as $3 \mu \mathrm{M}$ (Fig. 2B, top two panels). We also used the PARP cleavage assay to detect TNF- $\alpha$-induced apoptosis. Similarly, celastrol dosedependently potentiated the effect of TNF- $\alpha$-induced PARP cleavage; however, TNF- $\alpha$ alone and celastrol alone did not induce PARP cleavage (Fig. 2B, bottom second panel). These results showed that celastrol enhances the apoptotic effects of TNF- $\alpha$.

Celastrol inhibits TNF- $\alpha$-induced anti-apoptotic gene expression. Since TNF- $\alpha$-induced apoptosis was potentiated by celastrol, we investigated the effect of celastrol on TNF- $\alpha$ induced anti-apoptotic gene expression of cIAP1, cIAP2, FLIP, and Bcl-2. MDA-MB-231 cells were preincubated with celastrol for $12 \mathrm{~h}$ and subsequently stimulated with TNF- $\alpha$ for $12 \mathrm{~h}$, 


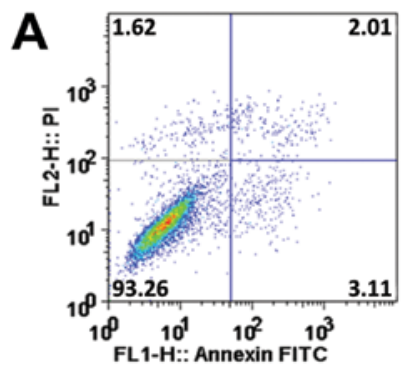

Vehicle

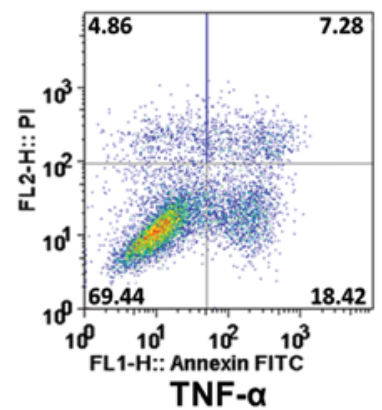

TNF- $\alpha$

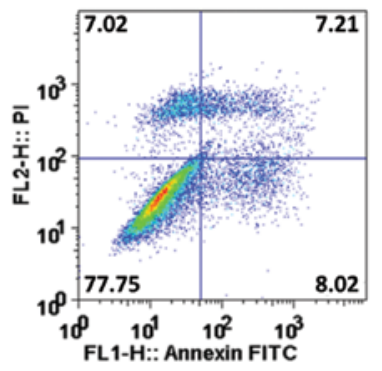

Celastrol

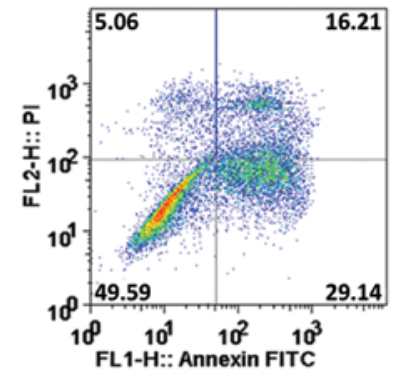

TNF- $\alpha+$ Celastrol

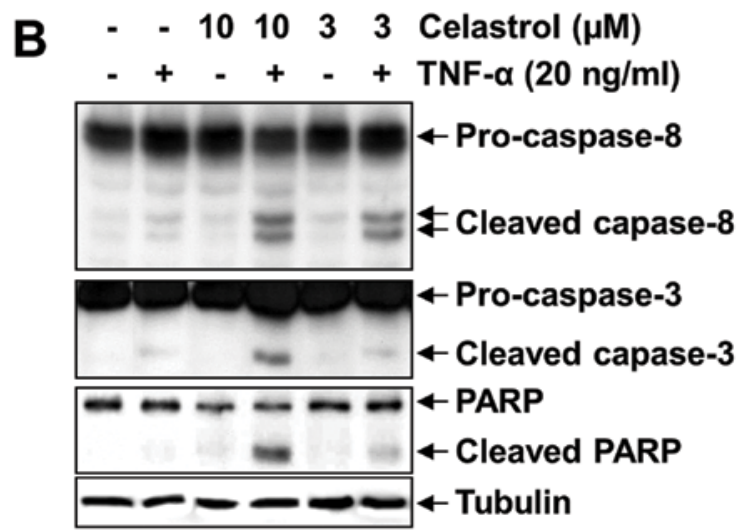

Figure 2. Effect of celastrol on tumor necrosis factor- $\alpha$ (TNF- $\alpha$ )-induced apoptosis. (A) MDA-MB-231 cells were pretreated with $10 \mu \mathrm{M}$ celastrol for $12 \mathrm{~h}$ and then incubated with $20 \mathrm{ng} / \mathrm{ml}$ TNF- $\alpha$ for $24 \mathrm{~h}$, and subsequently stained with Annexin V-FITC and propidium iodide, followed by analysis using a flow cytometer. Representative plots of one set of triplicate experiments are shown. Early apoptotic cells (Annexin- $\mathrm{V}^{+}$and $\left.\mathrm{PI}\right)$ were displayed in the lower right quadrant and late apoptotic cells $\left(\right.$ Annexin- $-\mathrm{V}^{+}$and $\mathrm{PI}^{+}$) are shown in the upper right quadrant. (B) MDA-MB-231 cells were pretreated with 3 and $10 \mu \mathrm{M}$ celastrol for $12 \mathrm{~h}$ and then incubated with $20 \mathrm{ng} / \mathrm{ml} \mathrm{TNF}-\alpha$ for $12 \mathrm{~h}$. Whole cell extracts were analyzed by western blot analysis using the indicated antibodies for cleaved caspase- 8 , cleaved caspase- 3 , cleaved PARP and tubulin.

and then the cIAP1, cIAP2, FLIP and Bcl-2 expression levels were analyzed by western blot analysis. TNF- $\alpha$ significantly induced the expression of anti-apoptotic proteins, whereas celastrol markedly suppressed TNF- $\alpha$-induced expression of all the proteins in a dose-dependent manner (Fig. 3).

Celastrol inhibits TNF- $\alpha$-induced invasion of MDA-MB-231 cells. Cancer cell invasion is a critical step of tumor metastasis (36). Whether celastrol modulates invasion activity was examined in vitro with a Matrigel invasion assay. MDA-MB-231 cells were seeded in the top chamber of a Matrigel invasion chamber and incubated with various concentrations of celas-

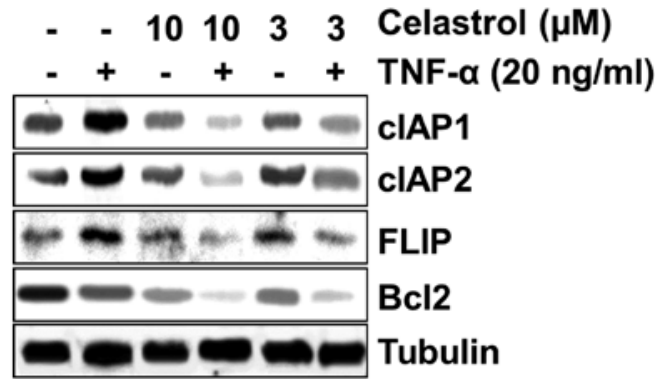

Figure 3. Effect of celastrol on the tumor necrosis factor- $\alpha$ (TNF- $\alpha$ )-induced anti-apoptotic gene expression. MDA-MB-231 cells were incubated with the indicated concentrations of celastrol for $12 \mathrm{~h}$ and then incubated with $20 \mathrm{ng} / \mathrm{ml}$ TNF- $\alpha$ for $12 \mathrm{~h}$. Whole cell extracts were analyzed by western blot analysis using the indicated antibodies for cellular inhibitor of apoptosis protein 1 (cIAP1), cIAP2, cellular FLICE-inhibitory protein (FLIP), B-cell lymphoma $2(\mathrm{Bcl}-2)$ and tubulin.
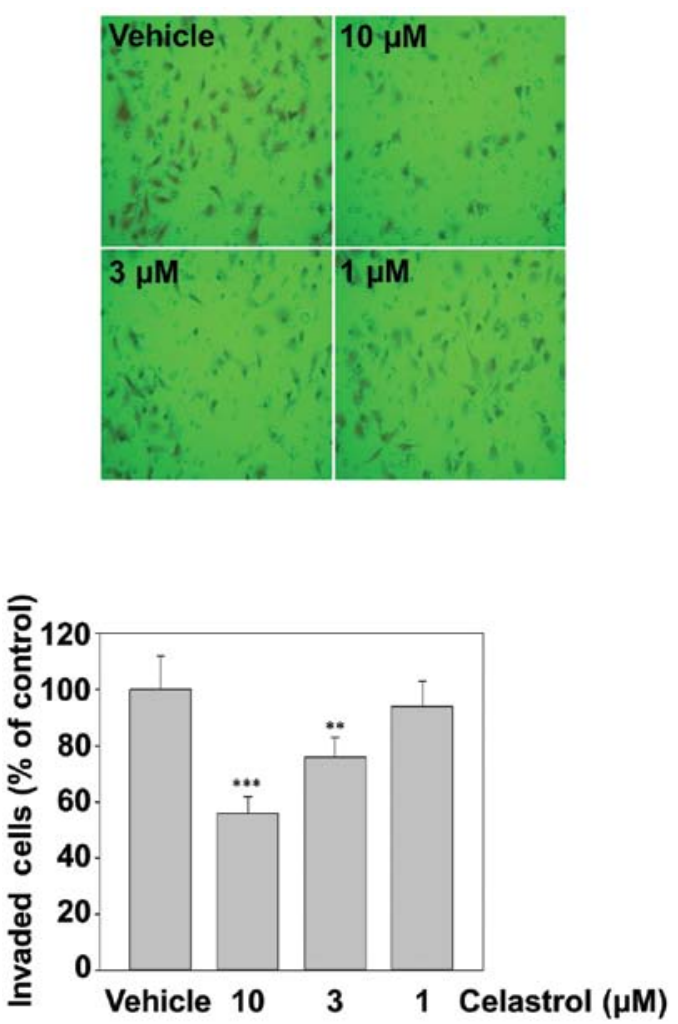

Figure 4. Effect of celastrol on the tumor necrosis factor- $\alpha$ (TNF- $\alpha$ )-induced invasion activities in breast cancer cells. MDA-MB-231 cells were incubated with the indicated concentrations of celastrol for $12 \mathrm{~h}$ and then incubated with $20 \mathrm{ng} / \mathrm{ml}$ TNF- $\alpha$ for $12 \mathrm{~h}$. MDA-MB-231 cells that invaded through the pores in the Matrigel-coated filters were fixed, stained and counted in five random fields visualized by microscopy (x100). Data are presented as the mean \pm standard deviation of three independent experiments. ${ }^{* *} \mathrm{P}<0.01$, ${ }_{* * * *} \mathrm{P}<0.001$, significant with respect to control.

trol for $12 \mathrm{~h}$ and subsequently with TNF- $\alpha(20 \mathrm{ng} / \mathrm{ml})$ for $12 \mathrm{~h}$. The cells that migrated to the lower chamber were significantly decreased by celastrol in a dose-dependent manner. This result could account for the anti-invasive activity of celastrol (Fig. 4).

Celastrol inhibits MMP-9 gene expression. In cancer cell metastasis, the degradation of ECM is essential and is associated with the overexpression of proteolytic enzymes including 
A

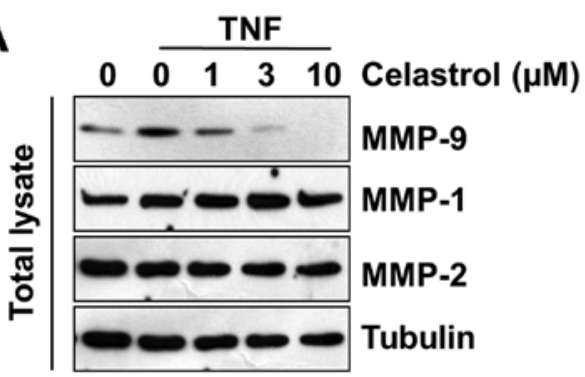

B

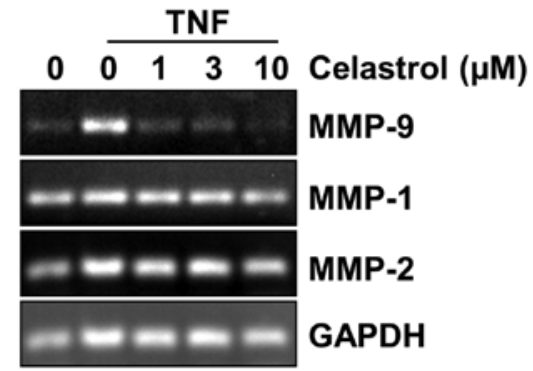

Figure 5. Effect of celastrol on the expression levels of metalloproteinases (MMPs). (A) MDA-MB-231 cells were treated with various concentrations of celastrol $(1,3$ and $10 \mu \mathrm{M})$ for $1 \mathrm{~h}$ and then treated with $20 \mathrm{ng} / \mathrm{ml}$ tumor necrosis factor- $\alpha$ (TNF- $\alpha$ ) for $12 \mathrm{~h}$. Whole cell extracts were analyzed by western blot analysis using the indicated antibodies for MMP-9, MMP-1, MMP-2 and tubulin. (B) MDA-MB-231 cells were incubated with celastrol and $20 \mathrm{ng} / \mathrm{ml} \mathrm{TNF}-\alpha$ for $12 \mathrm{~h}$. MMP expression levels were analyzed by realtime PCR as described in Materials and methods. GAPDH was used as the housekeeping gene control.

MMPs (3). MMP (MMP-1, MMP-2, and MMP-9) activation has been found in the metastasis of breast carcinoma cells. Therefore, the effects of celastrol on TNF- $\alpha$-induced MMP-1, MMP-2 and MMP-9 gene expression were examined. Western blot analysis was performed to investigate whether celastrol had inhibitory effects on TNF- $\alpha$-induced expression of MMPs. Although MMP-1 and MMP-2 protein expression levels remained unaffected, TNF- $\alpha$-induced expression of MMP-9 was prevented by celastrol in a dose-dependent manner (Fig. 5A). To determine whether the inhibition of MMP-9 gene expression by celastrol was due to a decreased level of transcription, we performed RT-PCR analysis and observed mRNA expression of MMP-9. In agreement with the above findings, celastrol treatment of the cells was found to decrease TNF- $\alpha$-induced MMP-9 mRNA expression in MDA-MB-231 cells in a dose-dependent manner, but it did not decrease MMP-1 and MMP-2 mRNA expression (Fig. 5B).

\section{Discussion}

Celastrol is a remedial ingredient in the root extracts of Thunder God Vine. Several screening studies on the molecular libraries of Chinese herbs have identified celastrol as a potent candidate with medicinal prospects for treating inflammatory diseases and cancer (37). Although several studies reported the possible involvement of celastrol in tumor metastasis, no study has reported the effect on TNF- $\alpha$-induced metastasis by celastrol in human breast cancer cells. The aim of the present study was to investigate the effect of celastrol on the TNF- $\alpha$ signaling pathway that mediates apoptosis and metastasis in human breast cancer cells.

The ability of anticancer drugs to induce the cellular apoptosis of cancer cells is an important function of cancer treatment $(38,39)$. Our results showed that celastrol inhibited the TNF- $\alpha$-induced expression of anti-apoptotic proteins such as cIAP1, cIAP2, FLIP and Bcl-2. Annexin V staining also showed that TNF- $\alpha$-induced apoptosis was enhanced by celastrol. In addition, celastrol affected TNF- $\alpha$-induced activation of caspase- 8 , caspase- 3 and PARP cleavage. In particular, celastrol had a considerable effect on TNF- $\alpha$ induced poly(ADP-ribose) polymerase cleavage, indicating that the apoptotic effects of TNF- $\alpha$ are enhanced by celastrol.

New anticancer agents have also been reported to control various other processes involved in the malignant transformation of cells, such as invasion and metastasis (40). Tumor metastasis is a multi-step and complex process that includes cell division and proliferation, proteolytic digestion of the ECM, cell migration through the basement membranes to reach the circulation system, and the remigration and growth of tumors at metastatic sites (11). MMPs play a key role in promoting tumor metastasis and overexpression of MMP-9 has been shown to be associated with the progression and invasion of tumors including mammary tumors $(11,41)$. Consequently, inhibiting MMP-9 expression may be critical in treating malignant tumors, including breast carcinoma.

We observed an inhibitory effect of celastrol on TNF- $\alpha$ induced invasion in MDA-MB-231 breast cancer cells. Accumulating evidence suggests that MMP-9 expression is strongly implicated in breast cancer invasion. Effective anticancer agents involved in anti-invasion have demonstrated the ability to downregulate MMP-9 expression (42). Our data revealed that celastrol inhibits TNF- $\alpha$-induced MMP-9 expression at both the mRNA and protein levels, but it does not influence MMP-1 and MMP-2 expression levels in MDA-MB-231 breast cancer cells. Notably, in our study, the inhibition of TNF- $\alpha$-induced invasion of MDA-MB-231 cells may correlate with that of the TNF- $\alpha$-induced MMP-9 expression. These results suggest that the anti-invasion effect of celastrol may be associated with the inhibition of MMP-9 expression.

In conclusion, the present study demonstrated that the natural compound celastrol exhibits effective antitumor properties. The observed antitumor activity inhibits the proliferation of cancer cells and induces apoptosis. In addition, our study provides evidence that celastrol can inhibit the invasion of breast cancer cells through the downregulation of MMP-9 expression. As tumor metastasis is often associated with poor prognosis and high mortality among breast cancer patients, there is a growing need to discover and develop new therapeutic strategies that target early tumor invasiveness or metastasis. In this regard, celastrol is a promising agent against breast cancer invasion and metastasis.

\section{Acknowledgements}

This study was partially supported by the National Natural Science Foundation of China (nos. 81360496 and 81160250). This study also received assistance from the Thousand Peoples Plan by Foreign Expert Bureau, China. 


\section{References}

1. Antonova L, Aronson K and Mueller CR: Stress and breast cancer: from epidemiology to molecular biology. Breast Cancer Res 13: 208, 2011

2. Decock J, Thirkettle S, Wagstaff L and Edwards DR: Matrix metalloproteinases: protective roles in cancer. J Cell Mol Med 15: 1254-1265, 2011.

3. Hoon DS, Ferris R, Tanaka R, Chong KK, Alix-Panabieres C and Pantel K: Molecular mechanisms of metastasis. J Surg Oncol 103: 508-517, 2011

4. Chambers AF and Matrisian LM: Changing views of the role of matrix metalloproteinases in metastasis. J Natl Cancer Inst 89: 1260-1270, 1997.

5. Woessner JF Jr: Matrix metalloproteinases and their inhibitors in connective tissue remodeling. FASEB J 5: 2145-2154, 1991.

6. Kim JM, Noh EM, Kwon KB, et al: Curcumin suppresses the TPA-induced invasion through inhibition of PKC $\alpha$-dependent MMP-expression in MCF-7 human breast cancer cells. Phytomedicine 19: 1085-1092, 2012.

7. Yu HY, Kim KS, Moon HI, Kim KM, Lee YC and Lee JH: JNP3, a new compound, suppresses PMA-induced tumor cell invasion via NF- $\mathrm{KB}$ down regulation in MCF-7 breast cancer cells. Biochem Biophys Res Commun 421: 190-196, 2012

8. Jin ML, Park SY, Kim YH, Park G and Lee SJ: Halofuginone induces the apoptosis of breast cancer cells and inhibits migration via downregulation of matrix metalloproteinase-9. Int J Oncol 44: 309-318, 2014.

9. Park SK, Hwang YS, Park KK, Park HJ, Seo JY and Chung WY: Kalopanaxsaponin A inhibits PMA-induced invasion by reducing matrix metalloproteinase-9 via PI3K/Akt- and PKCdelta-mediated signaling in MCF-7 human breast cancer cells. Carcinogenesis 30: 1225-1233, 2009.

10. Lee SO, Jeong YJ, Yu MH, et al: Wogonin suppresses TNF-alphainduced MMP-9 expression by blocking the NF-kappaB activation via MAPK signaling pathways in human aortic smooth muscle cells. Biochem Biophys Res Commun 351: $118-125,2006$.

11. Chung TW, Moon SK, Chang YC, et al: Novel and therapeutic effect of caffeic acid and caffeic acid phenyl ester on hepatocarcinoma cells: complete regression of hepatoma growth and metastasis by dual mechanism. FASEB J 18: 1670-1681, 2004.

12. Yan $C$ and Boyd DD: Regulation of matrix metalloproteinase gene expression. J Cell Physiol 211: 19-26, 2007.

13. Kim Y, Kang H, Jang SW and Ko J: Celastrol inhibits breast cancer cell invasion via suppression of NF- $\mathrm{BB}$-mediated matrix metalloproteinase-9 expression. Cell Physiol Biochem 28: 175-184, 2011.

14. Ling H, Zhang Y, Ng KY and Chew EH: Pachymic acid impairs breast cancer cell invasion by suppressing nuclear factor- $\kappa \mathrm{B}$ dependent matrix metalloproteinase-9 expression. Breast Cancer Res Treat 126: 609-620, 2011.

15. Zhang S, Li Z, Wu X, Huang Q, Shen HM and Ong CN: Methyl3 -indolylacetate inhibits cancer cell invasion by targeting the MEK1/2-ERK1/2 signaling pathway. Mol Cancer Ther 5: 3285-3293, 2006.

16. Taylor RC, Cullen SP and Martin SJ: Apoptosis: controlled demolition at the cellular level. Nat Rev Mol Cell Biol 9: 231-241, 2008.

17. Cotter TG, Lennon SV, Glynn JG and Martin SJ: Cell death via apoptosis and its relationship to growth, development and differentiation of both tumour and normal cells. Anticancer Res 10 : 1153-1159, 1990.

18. Urbanska K, Trojanek J, Del Valle L, et al: Inhibition of IGF-I receptor in anchorage-independence attenuates GSK-3beta constitutive phosphorylation and compromises growth and survival of medulloblastoma cell lines. Oncogene 26: 2308-2317, 2007.

19. Park JH, Kwon HY, Sohn EJ, et al: Inhibition of Wnt/ $\beta$-catenin signaling mediates ursolic acid-induced apoptosis in PC-3 prostate cancer cells. Pharmacol Rep 65: 1366-1374, 2013.

20. Hengartner MO: The biochemistry of apoptosis. Nature 407: $770-776,2000$

21. Degterev A, Boyce M and Yuan J: A decade of caspases. Oncogene 22: 8543-8567, 2003.
22. Irmler M, Thome M, Hahne M, et al: Inhibition of death receptor signals by cellular FLIP. Nature 388: 190-195, 1997.

23. Chao DT and Korsmeyer SJ: BCL-2 family: regulators of cell death. Annu Rev Immunol 16: 395-419, 1998

24. Wang CY, Mayo MW, Korneluk RG, Goeddel DV and Baldwin AS Jr: NF-kappaB antiapoptosis: induction of TRAF1 and TRAF2 and c-IAP1 and c-IAP2 to suppress caspase- 8 activation. Science 281: 1680-1683, 1998.

25. Yagita H, Takeda K, Hayakawa Y, Smyth MJ and Okumura K: TRAIL and its receptors as targets for cancer therapy. Cancer Sci 95: 777-783, 2004

26. Uchida M, Iwase M, Takaoka S, et al: Enhanced susceptibility to tumor necrosis factor-related apoptosis-inducing ligand-mediated apoptosis in oral squamous cell carcinoma cells treated with phosphatidylinositol 3-kinase inhibitors. Int J Oncol 30: 1163-1171, 2007.

27. Looi CY, Arya A, Cheah FK, et al: Induction of apoptosis in human breast cancer cells via caspase pathway by vernodalin isolated from Centratherum anthelminticum (L.) seeds. PLoS One 8: e56643, 2013.

28. Fulda S: Targeting apoptosis signaling pathways for anticancer therapy. Front Oncol 1: 23, 2011.

29. Larson CJ, Moreno JG, Pienta KJ, et al: Apoptosis of circulating tumor cells in prostate cancer patients. Cytometry A 62: 46-53, 2004.

30. Fehm T, Becker S, Becker-Pergola G, et al: Presence of apoptotic and nonapoptotic disseminated tumor cells reflects the response to neoadjuvant systemic therapy in breast cancer. Breast Cancer Res 8: R60, 2006.

31. Calixto JB, Campos MM, Otuki MF and Santos AR: Antiinflammatory compounds of plant origin. Part II. modulation of pro-inflammatory cytokines, chemokines and adhesion molecules. Planta Med 70: 93-103, 2004.

32. Sethi G, Ahn KS, Pandey MK and Aggarwal BB: Celastrol, a novel triterpene, potentiates TNF-induced apoptosis and suppresses invasion of tumor cells by inhibiting NF-kappaB-regulated gene products and TAK1-mediated NF-kappaB activation. Blood 109: 2727-2735, 2007

33. Yadav VR, Sung B, Prasad S, et al: Celastrol suppresses invasion of colon and pancreatic cancer cells through the downregulation of expression of CXCR4 chemokine receptor. J Mol Med 88: 1243-1253, 2010.

34. Jin HR, Jin SZ, Cai XF, et al: Cryptopleurine targets NF- $\kappa \mathrm{B}$ pathway, leading to inhibition of gene products associated with cell survival, proliferation, invasion, and angiogenesis. PLoS One 7: e40355, 2012

35. Wang $\mathrm{J}$ and Lenardo MJ: Roles of caspases in apoptosis, development, and cytokine maturation revealed by homozygous gene deficiencies. J Cell Sci 113: 753-757, 2000.

36. Comen E, Norton L and Massague J: Clinical implications of cancer self-seeding. Nat Rev Clin Oncol 8: 369-377, 2011.

37. Salminen A, Lehtonen M, Paimela $\mathrm{T}$ and Kaarniranta $\mathrm{K}$ : Celastrol: Molecular targets of Thunder God Vine. Biochem Biophys Res Commun 394: 439-442, 2010.

38. Chandra-Kuntal K, Lee J and Singh SV: Critical role for reactive oxygen species in apoptosis induction and cell migration inhibition by diallyl trisulfide, a cancer chemopreventive component of garlic. Breast Cancer Res Treat 138: 69-79, 2013.

39. Shi X, Zhao Y, Jiao Y, Shi T and Yang X: ROS-dependent mitochondria molecular mechanisms underlying antitumor activity of Pleurotus abalonus acidic polysaccharides in human breast cancer MCF-7 cells. PLoS One 8: e64266, 2013.

40. Li F, Li C, Zhang H, et al: VI-14, a novel flavonoid derivative, inhibits migration and invasion of human breast cancer cells. Toxicol Appl Pharmacol 261: 217-226, 2012.

41. Scorilas A, Karameris A, Arnogiannaki N, et al: Overexpression of matrix-metalloproteinase-9 in human breast cancer: a potential favourable indicator in node-negative patients. Br J Cancer 84: 1488-1496, 2001

42. Chen HW, Chao CY, Lin LL, et al: Inhibition of matrix metalloproteinase- 9 expression by docosahexaenoic acid mediated by heme oxygenase 1 in 12-O-tetradecanoylphorbol-13-acetateinduced MCF-7 human breast cancer cells. Arch Toxicol 87: 857-869, 2013. 